\title{
Comparative effectiveness of strategies to prevent weight gain among women with and at risk for breast cancer: a systematic review
}

\author{
Zoobia W Chaudhry ${ }^{1,6^{*}}$, Rochelle V Brown ${ }^{1}$, Oluwakemi A Fawole ${ }^{1,3,4}$, Renee Wilson ${ }^{1}$, Kimberly A Gudzune ${ }^{1,2,3}$, \\ Nisa M Maruthur ${ }^{1,3,4}$, Jodi Segal ${ }^{1,5}$ and Susan M Hutfless ${ }^{2}$
}

\begin{abstract}
Background: Obesity affects cancer risk and treatment outcomes. Preventing weight gain may prevent some cancers, improve cancer outcomes, reduce cancer recurrence and increase cancer-related survival. We performed a systematic review to identify strategies to prevent weight gain in individuals with or at risk for breast cancer.

Findings: We included 2 studies from 27,879 citations. In premenopausal women at risk for breast cancer, a low fat diet prevented weight gain at 12 months. Among women with breast cancer, effective strategies to prevent weight gain included low-fat dietary counseling with self-management techniques. One trial reported on cancer outcomes, mortality and adverse events. Low-fat dietary counseling wilth self-management techniques lowers the risk breast cancer relapse by $24 \%$ compared with less intensive counseling with maintenance of nutritional status goal. There was no difference in overall mortality and no adverse events were observed.

Conclusion: Limited evidence suggests that women with or at risk for breast cancer may successfully employ dietary and exercise strategies to prevent weight gain for at least one year. Low fat dietary counseling may improve cancer outcomes in women with breast cancer. Future studies should confirm these findings and evaluate the impact of weight gain prevention on cancer incidence, recurrence and survival.
\end{abstract}

\section{Introduction}

Overweight and obesity have been linked with increased risk of death from certain cancers such as breast cancer, renal cell carcinoma, pancreatic cancer, colon cancer and gynecologic cancers (Flegal et al. 2007). However, weight is one of the modifiable risk factors for cancer. Preventing weight gain could be an effective strategy to decrease the risk of malignancy in populations most at risk (Ballard-Barbash et al. 2012).

Cancer survivors with obesity have poorer cancerrelated outcomes than healthy weight patients including a higher number of second primary cancers and (Flegal et al. 2007; Daling et al. 2009) higher cancer recurrence (Flegal et al. 2007; Ewertz et al. 2011), cancer related

\footnotetext{
* Correspondence: zchaudh2@jhmi.edu

${ }^{1}$ Department of Medicine, Division of General Internal Medicine, Johns Hopkins University, Baltimore, MD, USA

${ }^{6}$ University Health Services, School of Medicine, Johns Hopkins University, 933 N. Wolfe Street, Baltimore, MD 21205, USA

Full list of author information is available at the end of the article
}

mortality and overall mortality rates (Flegal et al. 2007; Sinicrope et al. 2010; Ewertz et al. 2011; Protani et al. 2010). Overweight and obese individuals with cancer are also at risk of worse shortterm outcomes like poor wound healing, increased rates of postoperative infections (Albino et al. 2009; Doyle et al. 2010), and poor response to treatment (Bastarrachea et al. 1994). Overweight or obesity also increases the risk of other chronic conditions like cardiovascular disease and diabetes, that can influence cancer survivorship (Yancik et al. 2001). A recent meta-analysis found increased overall and cancer-specific mortality in obese breast cancer survivors (Protani et al. 2010). Interventions targeting the prevention of weight gain after cancer diagnosis and treatment could improve these outcomes and decrease recurrence.

Despite the theoretical benefits of weight gain prevention among populations with and at risk for breast cancer, we know of no prior synthesis of the weight gain prevention literature among this population. We aimed to review strategies to prevent weight gain in individuals 
at risk of breast cancer or with breast cancer. The strategies of interest were self-management, diet, physical activity, or combinations of these strategies.

\section{Methods}

\section{Literature search strategy}

We searched the following databases for primary studies: MEDLINE", Embase, the Cochrane Central Register of Controlled Trials, CINAHL and PsycINFO through June 2012. We developed and followed a standard protocol for this review following the Methods Guide for Effectiveness and Comparative Effectiveness Reviews (Owens et al. 2010). Additional details of the protocol are available in our full evidence report (Hutfless et al.). Title, abstract and full article reviews were performed by two independent reviewers. Conflicts were resolved by consensus adjudication. Relevant data were extracted from eligible intervention trials. Each article was serially abstracted by a first reviewer and then by a senior reviewer. This manuscript is a subset of studies from a report on strategies to prevent weight gain. The cancer section of the report included all study designs and all cancers, although the majority of evidence was for breast cancer.

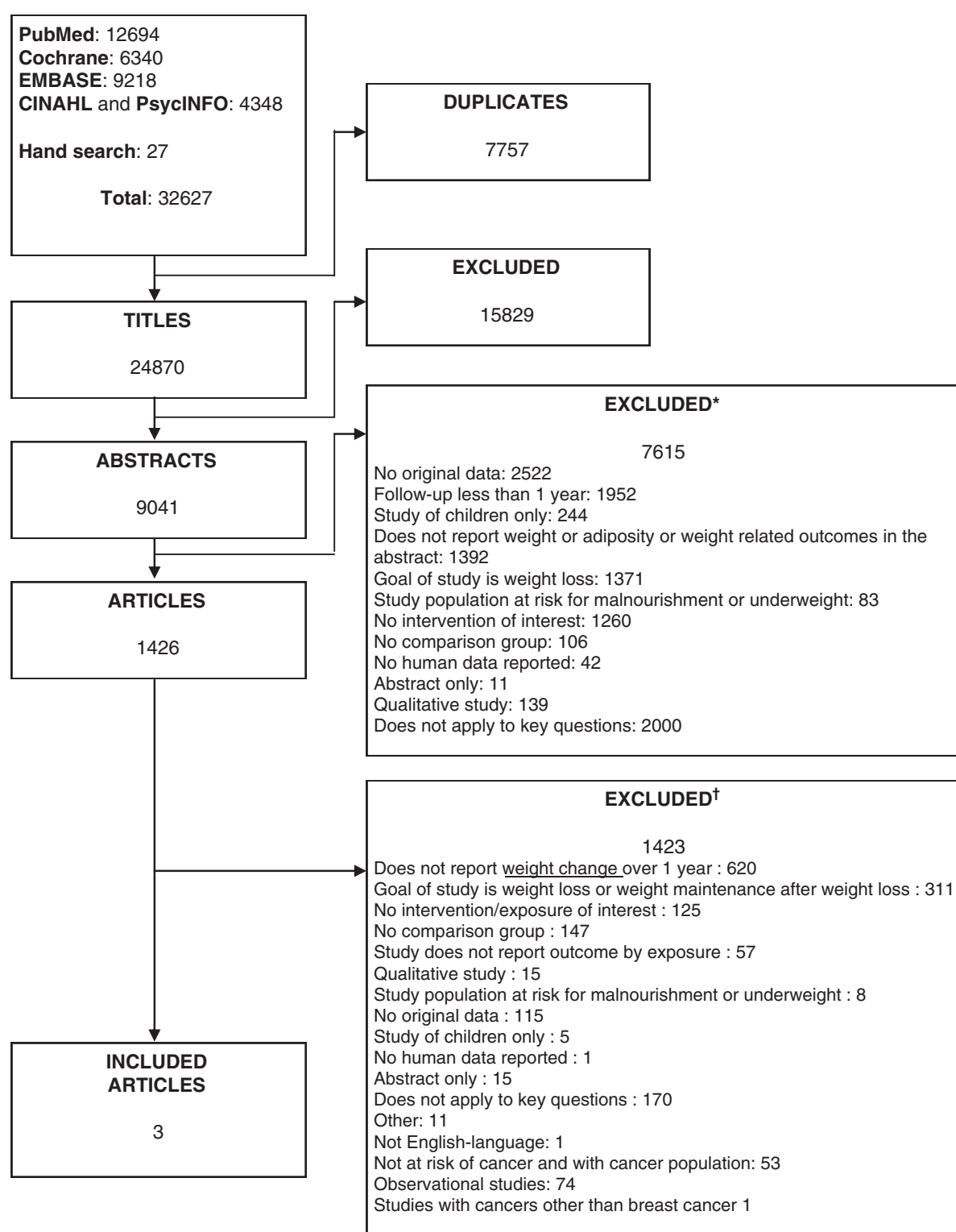

* Sum of excluded abstracts exceeds 7615 because reviewers were not required to agree on reasons for exclusion

${ }^{\dagger}$ Sum of excluded articles exceeds 1421 because reviewers were not required to agree on reasons for exclusion

Figure 1 Results of literature search. 
Weight outcomes of interest were body mass index (BMI), weight, and waist circumference. Cancer-related outcomes included cancer incidence, recurrence and mortality. We also sought quality of life, adherence, and safety outcomes. Safety outcomes included nutritional deficiencies, eating disorders, and activity-related injury. The data abstraction time points of interest for weightrelated outcomes were 1 year, 2 years, 5 years and the last reported time point after five years of follow up. For the other outcomes, we abstracted data for the last reported time point on or after one year. This study did not qualify as human-subjects research and, therefore, was not needed to be reviewed by the IRB.

\section{Quality assessment of individual studies}

Study quality was assessed using the Downs and Black methodologic quality assessment checklist (Downs and Black 1998). We used information on study quality to assess the risk of bias (using the internal validity items) of the studies. Two reviewers independently completed the checklist for each article and came to consensus for each item.

\section{Data synthesis}

We examined the study designs for qualitative similarities, and noted significant heterogeneity. Therefore, studies were not amenable to pooling with metaanalyses, and we instead calculated and displayed the between group mean differences with 95 percent confidence intervals (CI) for the individual studies, when provided.

We selected meaningful between-group difference thresholds as follows: $0.5 \mathrm{~kg}$ for weight, 0.2 units for BMI (based on a $0.5 \mathrm{~kg}$ change for an individual with a BMI of 27), and $1 \mathrm{~cm}$ for waist circumference. The meaningful threshold was annualized to account for the different durations of the studies. A P value $<0.05$ was considered statistically significant. For a strategy to be considered effective, it had to meet the meaningful between group difference and statistical thresholds.

\section{Results}

From the 27,897 entries identified from electronic resources, two interventional studies (Chlebowski et al. 2006; Djuric et al. 2002) (baseline $\mathrm{n}=2,559 ; 2,259$ analyzed) met our inclusion criteria (Figure 1). One trial was reported in two publications (Djuric et al. 2002; Chen et al. 2004).

Table 1 describes the characteristics of the included studies and their participants. Both studies were randomized trials conducted in the United States (Chlebowski et al. 2006; Djuric et al. 2002). The duration of the intervention was 12 months in both studies. One trial followed participants for an additional 48 months after the intervention (Chlebowski et al. 2006). The risk of bias was moderate for all studies due to lack of reporting on masking of the outcome assessors as to which intervention the participants were assigned to.

\section{Prevention of weight gain in women with or at risk of breast cancer}

One trial reported on an intervention to prevent weight gain in women at risk of cancer and another trial reported on an intervention among women with breast cancer (Chlebowski et al. 2006; Djuric et al. 2002). The trial of dietary interventions for prevention of weight gain in women at risk for cancer included premenopausal women $(n=160)$ with a family history of breast cancer and randomized these women to one of four diet groups for one year: control, low fat diet (LF), high fruits and vegetables diet (FV), or a combination of low fat and high fruits and vegetables diet (LFFV) (Table 2). As compared with the control group, the LF group lost weight. The FV and LFFV groups gained weight (Table 3). We were unable to calculate statistical significance for the between group differences based on the data reported. This study did not report on other outcomes of interest.

Chlebowski et al. (2006) randomized women $(\mathrm{n}=2,437)$ with breast cancer to a non-specific counseling group or an intervention group which received a combination of dietary counseling for a low fat diet with self-management techniques including goal setting, social support and dietary relapse prevention and management (Table 2).

Table 1 Characteristics of included studies

\begin{tabular}{|c|c|c|c|c|c|c|}
\hline \multirow{2}{*}{$\begin{array}{l}\text { Study } \\
\text { Years of recruitment }\end{array}$} & \multirow[t]{2}{*}{ Cancer population } & \multirow{2}{*}{$\begin{array}{l}\text { Study design } \\
\text { Trial duration }\end{array}$} & \multirow{2}{*}{$\begin{array}{l}\text { Stated goal of } \\
\text { weight gain prevention }\end{array}$} & \multicolumn{3}{|c|}{ Baseline characteristics of participants } \\
\hline & & & & Age & Race & Smoking status \\
\hline Djuric et al. (2002) & At-risk for breast cancer & $\begin{array}{l}\text { Single center } \\
\text { randomized trial }\end{array}$ & No & Mean Age & \%White & $N R$ \\
\hline 1997-1999 & & 12 months & & Overall: 38 years & Overall: $75 \%$ & \\
\hline Chlebowski et al. (2006) & Breast cancer & $\begin{array}{l}\text { Multicenter } \\
\text { randomized trial }\end{array}$ & No & Mean Age & \%White & Current smokers, $\mathrm{n}$ \\
\hline 1994-2001 & & 60 months & & Overall: 58.6 years & Overall: $85.1 \%$ & Overall: 162 \\
\hline
\end{tabular}

Abbreviations: NR Not reported. 


\begin{tabular}{|c|c|c|c|c|c|}
\hline \multirow[t]{3}{*}{ Study } & \multirow[t]{3}{*}{ Intervention } & \multicolumn{4}{|c|}{ Intervention arms } \\
\hline & & Control & Intervention Arm 1 & Intervention arm 2 & Intervention arm 3 \\
\hline & & & LF Group & FV group & LFFV group \\
\hline Djuric et al. (2002) & Dietary & $\begin{array}{l}\text { Received information on } \\
\text { Food Guide Pyramid from } \\
\text { National Dairy Council }\end{array}$ & $\begin{array}{l}\text { Low fat diet ( }<15 \% \text { calories from fat), one on one } \\
\text { counseling with dietitians, monthly group meetings, } \\
\text { written materials }\end{array}$ & $\begin{array}{l}\text { High fruits/vegetables diet } \\
\text { ( } \geq 9 \text { servings daily), one-on-one } \\
\text { counseling with dietitians, } \\
\text { monthly group meetings, } \\
\text { written materials }\end{array}$ & $\begin{array}{l}\text { Combination of low fat and } \\
\text { high fruits/vegetables diet, } \\
\text { one on one counseling with } \\
\text { dietitians, monthly group } \\
\text { meetings, written materials }\end{array}$ \\
\hline Chlebowski et al. (2006) & Self-management Dietary & $\begin{array}{l}\text { Maintained usual diet. } \\
\text { Had contact with dietician at } \\
\text { baseline and every } 3 \text { months } \\
\text { plus written materials }\end{array}$ & $\begin{array}{l}\text { Low fat diet ( }<15 \% \text { calories from fat) while } \\
\text { maintaining nutritional adequacy. In person } \\
\text { counseling sessions with focus on self-management } \\
\text { strategies: biweekly plus dietician visits every } 3 \text { months }\end{array}$ & NA & NA \\
\hline
\end{tabular}


Table 3 Differences in weight change from baseline to 1 year measured in kilograms among women with cancer

\begin{tabular}{|c|c|c|c|c|c|c|c|c|}
\hline Study & Control & $\begin{array}{l}\text { Intervention } \\
\text { arms }\end{array}$ & $\begin{array}{c}\text { Total } \\
\text { number } \\
\text { analyzed }\end{array}$ & $\begin{array}{l}\text { Baseline } \\
\text { weight }(\mathbf{k g}) \\
\text { control }\end{array}$ & $\begin{array}{c}\text { Baseline } \\
\text { weight }(\mathbf{k g}) \\
\text { Intervention arm }\end{array}$ & $\begin{array}{c}\text { Mean } \\
\text { change (kg) } \\
\text { control group }\end{array}$ & $\begin{array}{c}\text { Mean } \\
\text { change (kg) } \\
\text { intervention arm }\end{array}$ & $\begin{array}{c}\text { Mean } \\
\text { difference }(\mathbf{k g}) \\
\text { in group change }\end{array}$ \\
\hline $\begin{array}{l}\text { Djuric et al. } \\
\text { (2002) }\end{array}$ & $\begin{array}{l}\text { Diet/ } \\
\text { brochure }\end{array}$ & Low fat diet (LF) & 49 & 66.3 & 70.3 & -0.4 & -5 & -4.6 \\
\hline $\begin{array}{l}\text { Djuric et al. } \\
\text { (2002) }\end{array}$ & $\begin{array}{l}\text { Diet/ } \\
\text { brochure }\end{array}$ & $\begin{array}{c}\text { high fruits and } \\
\text { vegetables diet (FV) }\end{array}$ & 50 & 66.3 & 66.8 & -0.4 & 1.8 & 2.2 \\
\hline $\begin{array}{l}\text { Djuric et al. } \\
\text { (2002) }\end{array}$ & $\begin{array}{l}\text { Diet/ } \\
\text { brochure }\end{array}$ & $\begin{array}{l}\text { Combo diet } \\
\text { (LFFV) }\end{array}$ & 48 & 66.3 & 68.9 & -0.4 & 0 & 0.4 \\
\hline $\begin{array}{l}\text { Chlebowski } \\
\text { et al. (2002) }\end{array}$ & $\begin{array}{l}\text { Dietary } \\
\text { counseling }\end{array}$ & $\begin{array}{l}\text { Low fat diet + Self } \\
\text { management } \\
\text { counseling }\end{array}$ & 2164 & 72.6 & 72.7 & 0.2 & -2.1 & -2.3 \\
\hline
\end{tabular}

As compared with the non-specific counseling group, the low-fat group lost weight at one year. (Table 3) Similarly, BMI was $0.8 \mathrm{~kg} / \mathrm{m}^{2}$ lower in the low fat group as compared with the non-specific counseling group at one year.

In this study, women who received low-fat dietary counseling had a $24 \%$ lower risk of breast cancer relapse and $29 \%$ lower risk of breast cancer recurrence than those who received non-specific counseling, after 5 years of follow up. There was no reported risk reduction in overall mortality. The study stated that no adverse events were associated with the dietary interventions.

\section{Discussion}

Despite the rich literature on association of being overweight and obese to the risk of developing breast cancer (Ballard-Barbash et al. 2012; Rock et al. 2012; Norat et al. 2008; Norat et al. 2010; World Cancer Research Fund/ American Institute for Cancer Research 2007) and to the poorer outcomes after the diagnosis (Ballard-Barbash et al. 2012); we identified only two studies, with strategies for weight maintenance, for inclusion in our review. Strategies that were effective included use of a low fat diet in premenopausal women with a family history of breast cancer; and group counseling on monitoring fat intake resulting in low fat diet in women with breast cancer. The present review highlights strategies that may effectively prevent weight gain among women with or at risk of breast cancer.

World Cancer Research Fund/American Institute for Cancer Research (WCRF/AICR) 2007 report (World Cancer Research Fund/American Institute for Cancer Research 2007) and American Cancer Society (ACS) guidelines on Nutrition and Physical Activity for Cancer Prevention (Kushi et al. 2012) recommended that individuals maintain a lean weight to prevent cancer. A body of original research also suggests that being overweight and obese increases the risk of postmenopausal breast cancer (Ewertz et al. 2011; Protani et al. 2010; Norat et al. 2008). Most of the data come from the cohort studies of breast cancer (Norat et al. 2008; Goodwin et al. 1999).
Studies have shown that breast cancer is diagnosed at early stages now and most of the patients are obese or over weight at the time of diagnosis (Pekmezi and Demark-Wahnefried 2011). It is further complicated by post- diagnosis weight gain secondary to several factors like side affects from the cancer treatment or lack of physical activity after the diagnosis (Chlebowski et al. 2002). The research lacks in the field of interventional studies to indicate how to achieve the goal of weight gain prevention at the different stages of cancer survivors i.e. at the time of diagnosis, during and post-treatment. Few interventional studies (Demark-Wahnefried et al. 2012) have reported the strategies of weight maintenance in individuals with breast cancer but were excluded from this review mainly due to lack of having one year follow up and lack of reporting on meaningful weight related outcomes.

The most extensive review published by WCRF/AICR (World Cancer Research Fund/American Institute for Cancer Research 2007) in 2007 recognized the lack of evidence about prevention of weight gain in cancer survivors. The ACS's Nutrition and Physical Activity for Cancer Survivors (Rock et al. 2012) guidelines also acknowledged that most of the evidence related to weight maintenance or weight loss strategies does not come from studies of cancer survivors. Dietary and nutritional requirement are very different depending on the stage and type of cancer immediately post diagnosis. Thus ACS recommends maintaining healthy weight and consult with registered dietitian who is also certified specialist in oncology, achieve and maintain healthy weight, engage in regular exercise and consume diet high in vegetable, fruits and whole grains. The evidence to support these recommendations is derived from studies on general population and not cancer survivors. Research also lacks to show any strong benefit or risk in terms of mortality with adopting the weight maintenance strategies in early stages of cancer diagnosis in overweight or obese individuals.

\section{Limitations}

Our review is limited by the paucity of the literature evaluating weight maintenance interventions in patients with or at risk for breast cancer. Also, one of the studies 
did not report variance estimates, so we were unable to calculate confidence intervals for our results to evaluate the statistical significance of the study results. Only one (Djuric et al. 2002) of the included studies had the stated goal of weight maintenance. While our results are suggestive for the women with breast cancer, we were unable to identify studies including other types of cancer, studies with men or individuals from different ethnic backgrounds.

\section{Conclusions}

We identified two RCTs supporting strategies to prevent weight gain among women with or at risk of breast cancer, which included dietary counseling on low fat diet and weight reduction with low fat diet. Additional research is needed to confirm these strategies as effective in preventing weight gain and to assess whether weight gain prevention interventions also result in decreased cancer incidence, recurrence and mortality in other types of cancers and different populations.

\section{Consent}

Our study population for a systematic review is medical publications. No individuals were directly contacted or studied as part of our work.

\section{Competing interests}

The authors declared that they have no competing interests.

\section{Authors' contributions}

ZC, RB, OF, RW, KG, NM and SH abstracted data from the articles. ZC, RB, KG, JS and SH drafted and reviewed the manuscript. All authors read and approved the final manuscript.

\section{Funding}

This project was funded under Contract No. 290-2007-10061-I from the Agency for Healthcare Research and Quality, U.S. Department of Health and Human Services. The authors of this report are responsible for its content. Statements in the report should not be construed as endorsement by the Agency for Healthcare Research and Quality or the U.S. Department of Health and Human Services.

\section{Financial disclosure statement}

None of the investigators has any affiliations or financial involvement that conflicts with the material presented in this report.

\section{Author details}

${ }^{1}$ Department of Medicine, Division of General Internal Medicine, Johns Hopkins University, Baltimore, MD, USA. ²Department of Medicine, Division of Gastroenterology and Hepatology, Johns Hopkins University, Baltimore, MD, USA. ${ }^{3}$ Welch Center for Prevention, Epidemiology, and Clinical Research, Johns Hopkins University, Baltimore, MD, USA. ${ }^{4}$ Department of Epidemiology, Johns Hopkins University, Baltimore, MD, USA. ${ }^{5}$ Department of Health Policy and Management, Johns Hopkins Bloomberg School of Public Health, Baltimore, MD, USA. ${ }^{6}$ University Health Services, School of Medicine, Johns Hopkins University, 933 N. Wolfe Street, Baltimore, MD 21205, USA.
}

Received: 21 May 2013 Accepted: 30 May 2013

Published: 26 June 2013

\section{References}

Albino FP, Koltz PF, Gusenoff JA (2009) A comparative analysis and systematic review of the wound-healing milieu: implications for body contouring after massive weight loss. Plast Reconstr Surg 124(5):1675-1682

Ballard-Barbash R, Friedenreich CM, Courneya KS, Siddiqi SM, McTiernan A, Alfano CM (2012) Physical activity, biomarkers, and disease outcomes in cancer survivors: a systematic review. JNCI J Natl Cancer Inst 104(11):815-840

Bastarrachea J, Hortobagyi GN, Smith TL et al (1994) Obesity as an adverse prognostic factor for patients receiving adjuvant chemotherapy for breast cancer. Ann Intern Med 120(1):18-25

Chen G, Heilbrun LK, Venkatramanamoorthy R, Maranci V, Redd JN, Klurfeld DM, Djuric Z (2004) Effects of low-fat and/or high-fruit-and-vegetable diets on plasma levels of 8-isoprostane-F2 alpha in the Nutrition and Breast Health study. Nutr Cancer 50(2):155-160

Chlebowski RT, Aiello E, McTiernan A (2002) Weight loss in breast cancer patient management. J Clin Oncol 20:1128-1143

Chlebowski RT, Blackburn GL, Thomson CA et al (2006) Dietary fat reduction and breast cancer outcome: interim efficacy results from the women's intervention nutrition study. J Natl Cancer Inst 98(24):1767-1776

Daling JR, Porter PL, Tang MT, Malone KE (2009) Relationship between potentially modifiable lifestyle factors and risk of second primary contralateral breast cancer among women diagnosed with estrogen receptor-positive invasive breast cancer. J Clin Oncol 27(32):5312-5318

Demark-Wahnefried W, Campbell KL, Hayes SC (2012) Weight management and its role in breast cancer rehabilitation. Cancer 118(8 Suppl):2277-2287

Djuric Z, Poore KM, Depper JB et al (2002) Methods to increase fruit and vegetable intake with and without a decrease in fat intake: Compliance and effects on body weight in the nutrition and breast health study. Nutr Cancer 43(2):141-151

Downs SH, Black N (1998) The feasibility of creating a checklist for the assessment of the methodological quality both of randomised and nonrandomised studies of health care interventions. J Epidemiol Community Health 52(6):377-384

Doyle SL, Lysaght J, Reynolds JV (2010) Obesity and post-operative complications in patients undergoing non-bariatric surgery. Obes Rev 11(12):875-886

Ewertz M, Jensen MB, Gunnarsdottir KA et al (2011) Effect of obesity on prognosis after early-stage breast cancer. J Clin Oncol 29:25-31

Flegal KM, Graubard BI, Williamson DF, Gail MH (2007) Cause-specific excess deaths associated with underweight, overweight, and obesity. JAMA 298 (17):2028-2037

Goodwin PJ, Ennis M, Pritchard Kl et al (1999) Adjuvant treatment and onset of menopause predict weight gain after breast cancer diagnosis. J Clin Oncol $17: 120-129$

Hutfless S, Maruthur NM, Wilson RF, Gudzune KA, Brown R, Lau B, Fawole OA, Chaudhry ZW, Anderson CAM, Segal JB (2013) Strategies to Prevent Weight Gain Among Adults Comparative Effectiveness Review No. 97 . (Prepared by The Johns Hopkins University Evidence - base d Practice Center under Contract No. 290 - 2007 - 10061 - I. ) AHRQ Publication No. 13 - EHC029EF. Agency for Healthcare Research and Quality, Rockville, MD, www.effectivehealthcare.ahrq.gov

Kushi LH, Doyle C, McCullough M, Rock CL, Demark-Wahnefried W, Bandera EV, Gapstur S, Patel AV, Andrews K, Gansler T (2012) American cancer society 2010 nutrition and physical activity guidelines advisory committee. American cancer society guidelines on nutrition and physical activity for cancer prevention: reducing the risk of cancer with healthy food choices and physical activity. CA Cancer J Clin 62(1):30-67

Norat T, Chan D, Lau R, Vieira R (2008) The Associations Between Food, Nutrition and Physical Activity and the Risk of Breast Cancer, WCRF/AICR Systematic Literature Review Continuous Update Project Report. World Cancer Research Fund/American Institute for Cancer Research, London

Norat T, Chan D, Lau R, Aune D, Vieira R (2010) The Associations Between Food, Nutrition and Physical Activity and the Risk of Colorectal Cancer, WCRF/ AICR Systematic Literature Review Continuous Update Project Report. World Cancer Research Fund/American Institute for Cancer Research, London

Owens DK, Lohr KN, Atkins D et al (2010) AHRQ series paper 5: grading the strength of a body of evidence when comparing medical interventionsagency for healthcare research and quality and the effective health-care program. J Clin Epidemiol 63(5):513-523

Pekmezi DW, Demark-Wahnefried W (2011) Updated evidence in support of diet and exercise interventions in cancer survivors. Acta Oncol 2:167-178 
Protani M, Coory M, Martin JH (2010) Effect of obesity on survival of women with breast cancer: systematic review and meta-analysis. Breast Cancer Res Treat 123:627-635

Rock CL, Doyle C, Demark-Wahnefried W et al (2012) Nutrition and physical activity guidelines for cancer survivors. CA Cancer J Clin 62(4):243-274

Sinicrope FA, Foster NR, Sargent DJ, O'Connell MJ, Rankin C (2010) Obesity is an independent prognostic variable in colon cancer survivors. Clin Cancer Res 16:1884-1893

World Cancer Research Fund/American Institute for Cancer Research (2007) Food, Nutrition, Physical Activity, and the Prevention of Cancer: A Global Perspective. AICR, Washington, DC

Yancik R, Wesley MN, Ries LA, Havlik RJ, Edwards BK, Yates JW (2001) Effect of age and comorbidity in postmenopausal breast cancer patients aged 55 years and older. JAMA 285(7):885-892

doi:10.1186/2193-1801-2-277

Cite this article as: Chaudhry et al: Comparative effectiveness of

strategies to prevent weight gain among women with and at risk for breast cancer: a systematic review. SpringerPlus 2013 2:277.

\section{Submit your manuscript to a SpringerOpen ${ }^{\circ}$} journal and benefit from:

- Convenient online submission

- Rigorous peer review

- Immediate publication on acceptance

- Open access: articles freely available online

- High visibility within the field

- Retaining the copyright to your article

Submit your next manuscript at $\gg$ springeropen.com 